GLOBAL JOURNAL OF GEOLOGICAL SCIENCES VOL. 15, 2017: 57-64

\title{
LITHOLOGIC FEATURES AND URANIUM POSSIBILITIES OF THE GRANITES OF PUPULE, ADAMAWA MASSIF N.E. NIGERIA
}

I. V. HARUNA

(Received 11 November 2016; Revision Accepted 3 February 2017)

\begin{abstract}
Preliminary lithologic and uranium investigation conducted in Pupule and environs to investigate further the area of uranium mineralisation in the neighbouring district revealed that the area is not attractive for further uranium search. Geologic field mapping shows that the area like most other parts of the region is underlain predominantly by finegrained granites, equigranular granites and porphyritic granites. Data obtained from the radiometric investigation indicate fairly enhanced radiometric values of only $200 \mathrm{cps}$ above the background counts of $100 \mathrm{cps}$. Data treatment and interpretation of the result suggest that the fairly enhanced radioactivity in the fine-grained granite, southeast of Pupule, may be related to high background values rather than concentration of uranium minerals in this rock that may justify further more detailed investigation.
\end{abstract}

KEYWORDS: Uranium, Granite, Geology, Pupule, Nigeria

\section{INTRODUCTION}

Nigeria does not only lie in the same region with countries in which uranium exploration has produced encouraging results but shares common boundary with these countries. For instance, Nigeria is bordered by Niger Republic in the northern part and by Chad Republic in the northeasthern part (Fig. 1). In both countries, uranium exploration has led to economic discoveries. For instance, according to a Joint Report by the Organisation for Economic Co-operation and Development (OECD) (2014), uranium exploration began in Niger Republic in 1956 in the Arlit area and by 1957 it has yielded the first discovery in the sandstone at Azelik. Encouraged by this discovery, further studies of the sandstone resulted in the discoveries of Abokurum, Madaouela, Arlette, Ariege, Artois and Taza, Imouraren and Akouta deposits. By 1971, production from the Arlette deposit had commenced by open-pit mining. Production from Arkouta and Akola deposits started in 1974 by underground operation. In 2004,
COGEMA (now AREVA) and the government of Niger signed an agreement to undertake a major exploration programme and in subsequent years previously discovered deposits have been delineated and evaluated. In 2006, the China National Nuclear Corporation (CNNC) signed an agreement to develop the Azelik-Abokurum deposit and by the end of December 2010, first production was reported. All uranium deposits in Niger are located within the Mersol̈ Basin similar to the sedimentary basins in Nigeria.

In the Chad Republic, an area of about $10,000 \mathrm{~km}^{2}$ in the south western part of the country was covered by aerial radiometric and magnetic surveys between 1972 and 1980. As a result, several radiometric anomalies were found in both granitic and sedimentary terrain and vein-type uranium mineralization in the Lere alkaline granite. In 1978, a UNDP-supported project resulted in the discovery of uranium mineralization in the syenitic Mayo-kebbi area near the border with Cameron Republic which also shares its western border with Nigeria.

I. V. Haruna, Department of Geology, Modibbo Adama University of Technology, Yola, Nigeria. 


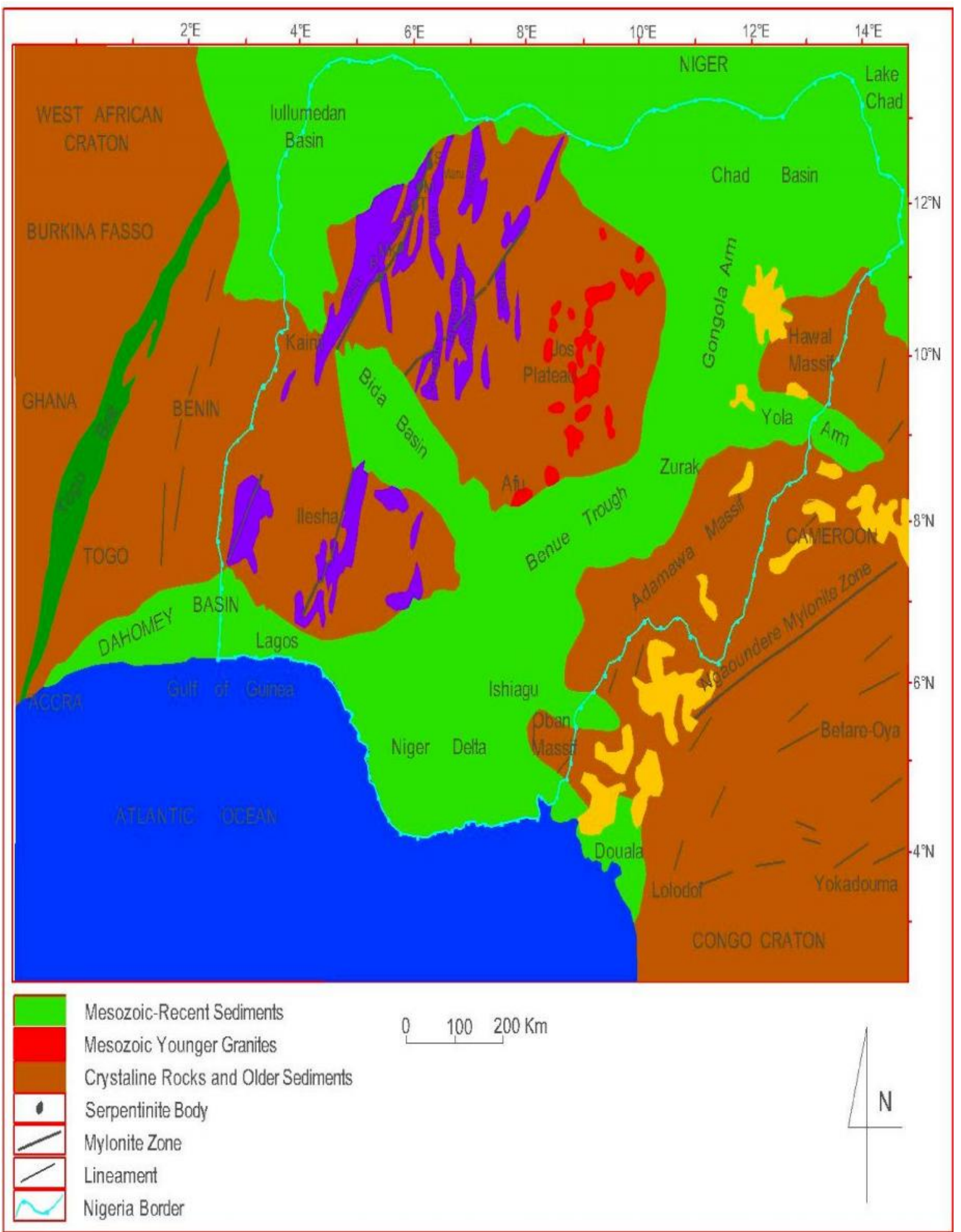

Fig. 1: Geology of Nigeria and the adjoining areas (modified after Geological Survey of Nigeria, Geological Survey of Nigeria, 1974) 
In Nigeria, regional survey in the early 1980s involving airborne radiometry for the entire national territory was carried out. The result of the survey lent fresh direction and impetus for uranium exploration and identified the northeastern part of the country as the potential region for further uranium prospecting. Subsequent investigations and geological mapping led to the discovery of some vein-type and sediment-hosted uranium occurrences. These include the Mika deposit, Ghumchi deposit; Zona deposit and the Kanawa deposit (Okujeni and others, 1988; Funtua et al., 1992; Ogunleye and Okujeni, 1993; Funtua and Okujeni, 1996). This result, coupled with the geological similarity and proximity of Nigeria to the aforementioned countries with economic uranium deposits, suggest that further exploration work, especially in areas with uranium prospects may reveal more and better deposits.

In recent years, Haruna et al., (2011a), Haruna et al., (2011b), Haruna et al., (2011c), Haruna et al., (2012a), Haruna et al., (2012b), lunched a ground radiometric programme in the vicinity of some of these previously discovered occurrences and other promising areas to see if the existing occurrences can be expanded or new ones discovered. The results were encouraging as they revealed indications of radiometric anomalies that may be followed up with more detailed investigations. The present work is a continuation of the programme. It examines the lithologic features and uranium possibilities of the granites of Pupule and environs.

\section{FIELD PROCEDURE}

The field work involved rock sample collection, rocks description and radiometric measurements along traverses. Fresh rock samples were collected at stations with noticeable changes in texture, structure, mineralogy and colour. Weathered rock samples were also investigated for uranium minerals. The collected fresh samples were properly labelled in the field and subsequently transported to the petrology laboratory of the department of geology, Modibbo Adama University of Technology for thin section preparation and petrographic study.
Radiometric survey was carried out using a McPhar model TC-33A portable gamma ray scintillometer (specifically designed for use in uranium prospecting) and a Global Positioning System (GPS) Receiver for taking coordinates. Before the commencement of the actual radiometric measurement in the study area, measurements of radioactivity in granitic rocks outside the study area were made in order to have an idea of background values. Subsequently, traverses were made in the study area with the scintillometer turned on and held about $1 \mathrm{~m}$ above the ground.

\section{RESULTS}

\section{Lithology and field characteristics}

The predominant rock units of the study area were found to be equigranular medium-grained granites and porphyritic granites with subordinate fine-grained granite (Fig. 2). Although texturally different, these rocks show no significant variation in mineralogy.

\section{Fine-grained Granite}

The fine-grained granites like most rocks in the area are massive having practically no linear or planar structures. The rock is fine-grained and show very little or no variation in texture. The colour is generally brown with grey patches in a few locations. Inclusions are clearly lacking. This is in sharp contrast with similar rocks with inclusions occurring as irregular bodies and as vein-like lenses within the equigranular granite having sharp contact relationship around Monkin in the far southern part of the study area.

Fine-grained granite is of restricted occurrence in the study area. It occurs as a low-lying intrusive only in south-eastern part of the study area. Here, the rock occupies a linear stretch of land that extends for about three kilometres in a SE-NW direction. Mineralogy of the fine-grained granite is similar to those of other rock units in the area. It consists essentially of microcline, Kfeldspar, quartz, plagioclase, biotite and accessory apatite, zircon sphene, and opaque (Table 1). 


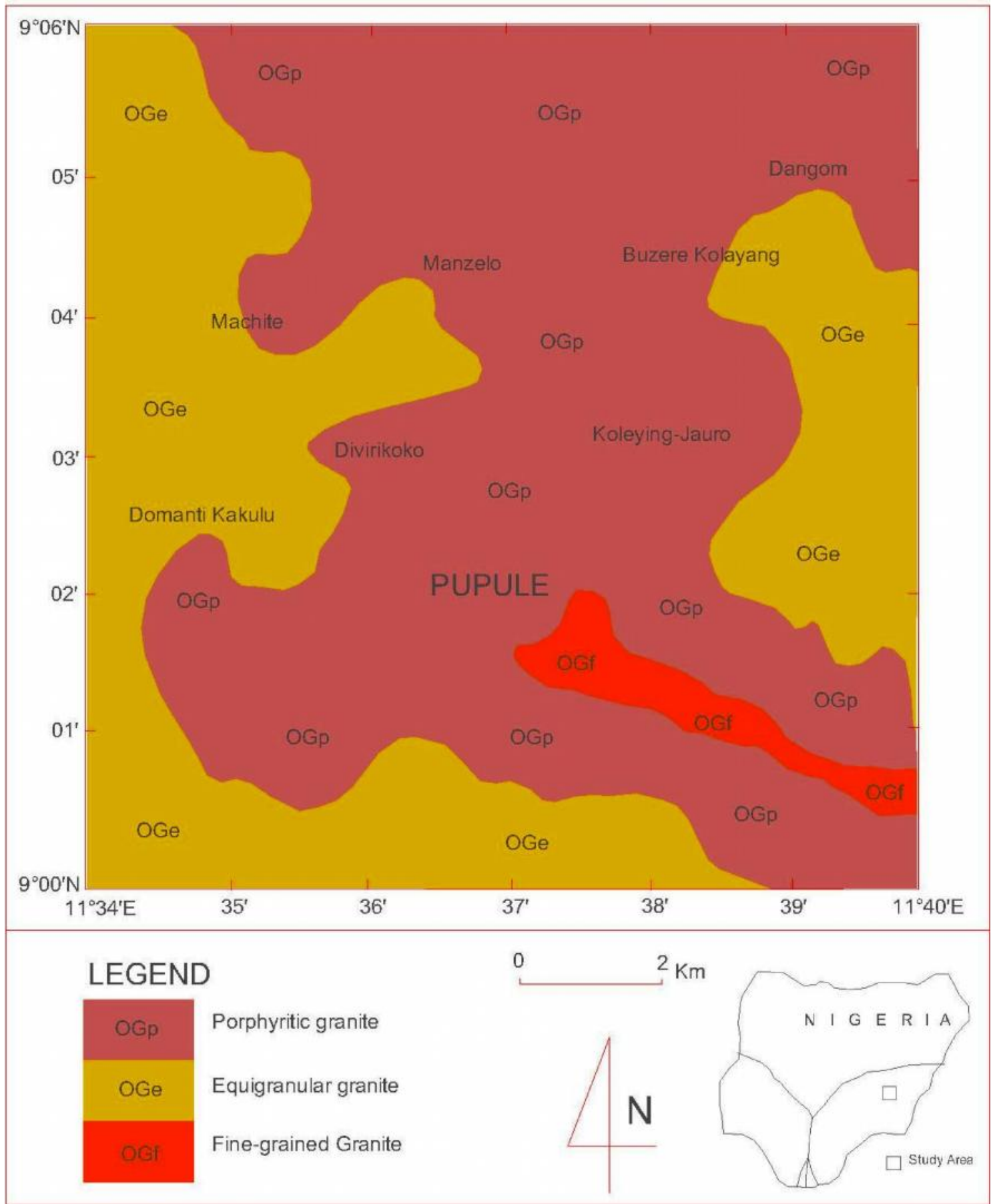

Fig. 2: Geology of Pupule (present work)

\section{Equigranular Granite}

The equigranular granites, like the fine-grained granites are massive with practically no structures. They are predominantly medium-grained but vary from this texture to coarse-grained in some places especially towards their boundaries with the porphyritic granites. In a few, locations the equigranular granites are slightly foliated with the foliation marked by feldspar and biotite crystals. Mafic inclusions, irregular in shape are sporadically observed in a few places. Quartz-feldspar pegmatites are common probably representing late fluid segregation. Contacts between the equigranular granites and the fine-grained granites are both sharp and trancitional In terme of rolnior twon variaties of equigranular granites are distinguishable in the field. These are the pink and the grey varieties. Both are texturally similar but only slightly variable in mineralogy.

The equigranular granites are wide spread in the area, occupying a vast expanse of land from the eastern to southern and western parts of the study area. In these areas, they occur as low-lying subcircular plutons except in the north-western part where they form a chain of hills in a west-east direction.

Identifiable minerals in the equigranular granites include: potassium feldspar, microcline, quartz, plagioclase, biotite with accessory sphene, zircon and opaques (Table 1). 


\section{Porphyritic Granite}

The porphyritic granites consist of phenocrysts of microcline (measuring about $15 \mathrm{~mm} \times 25 \mathrm{~mm}$ to about $30 \mathrm{~mm} \times 35 \mathrm{~mm}$ ) set in a medium- to coarse-grained texture ranging in size from about $1.5 \mathrm{~mm} \times 2 \mathrm{~mm}$ to about $3 \mathrm{~mm} \times 3.5 \mathrm{~mm}$. They are relatively homogeneous, but like the equigranular granites, two varieties are distinguishable in the field: these are the pink and grey varieties. Although the two varieties are slightly variable in mineralogy, they have the same gradational contact relationship with the equigranular varieties. The transition from equigranular granite to porphyritic granite is marked by gradual increase in the number of microcline phenocrysts.

Like the porphyritic granites of other parts within this region, the porphyritic granites of this area occur as massive intrusions in which the acidic composition grades into a fairly basic variety at the margins of the intrusions. Ferromagnesian minerals are mainly biotite.
Composition and texture of porphyritic granite changes as one traverses the intrusions from the center to the margins. At the center, feldspar phenocrysts are crowded and gradually changes towards the edges where they are less crowded, few and scattered.

Acid segregation such as quartz-feldspar pegmatites, common in the equigranular granites, are scarce in the porphyritic granites. The rock contains less enclaves but within the marginal facies, inclusions of basic rocks (probably patches of migmatites) are frequently seen.

Porphyritic granites are widespread and extensive in the central to northern parts of the study area. The greater portion of the range of hills in the northern part of Pupule is underlain by porphyritic granites.

The porphyritic granites consist principally of microcline, quartz, plagioclase, K-feldspar and biotite (Table 1).

Table 1: Modal composition of fifteen (15) granite samples from Pupule area

\begin{tabular}{llll}
\hline & Equigranular Granite & Porphyritic Granite & Fine-grained Granite \\
\hline Quartz & 17 & 23 & 20 \\
Microcline & 12 & 9 & 8 \\
K-Feldspar & 42 & 40 & 47 \\
Plagioclase & 18 & 15 & 14 \\
Biotite & 4 & 5 & 5 \\
Muscovite & 3 & 2 & - \\
Apatite & - & 2 & 1 \\
Zircon & 1 & 1 & 2 \\
Sphene & 2 & 1 & 1 \\
Opaque & 1 & 2 & 2 \\
\hline
\end{tabular}

\section{Radiometric Data Treatment and Presentation}

The data obtained from the survey were presented in appendix I and summarised in Table 2. To provide a clear and pictorial view of the result, a chart and Isorad map of same data were also presented (Fig.3 and Fig. 4).

Table 2: Percentage Frequencies of Radioactivity Values (cps) in the granites of Pupule Area

\begin{tabular}{|l|l|l|}
\hline $\begin{array}{l}\text { Class of Radioactivity } \\
\text { (cps) }\end{array}$ & Number of Frequency & Percentage Frequency \\
\hline $00-50$ & 164 & 75.58 \\
$51-100$ & 45 & 20.74 \\
$101-150$ & 3 & 1.38 \\
$151-200$ & 5 & 2.3 \\
$201-250$ & 0 & 0 \\
\hline Total & 217 & 100 \\
\hline
\end{tabular}




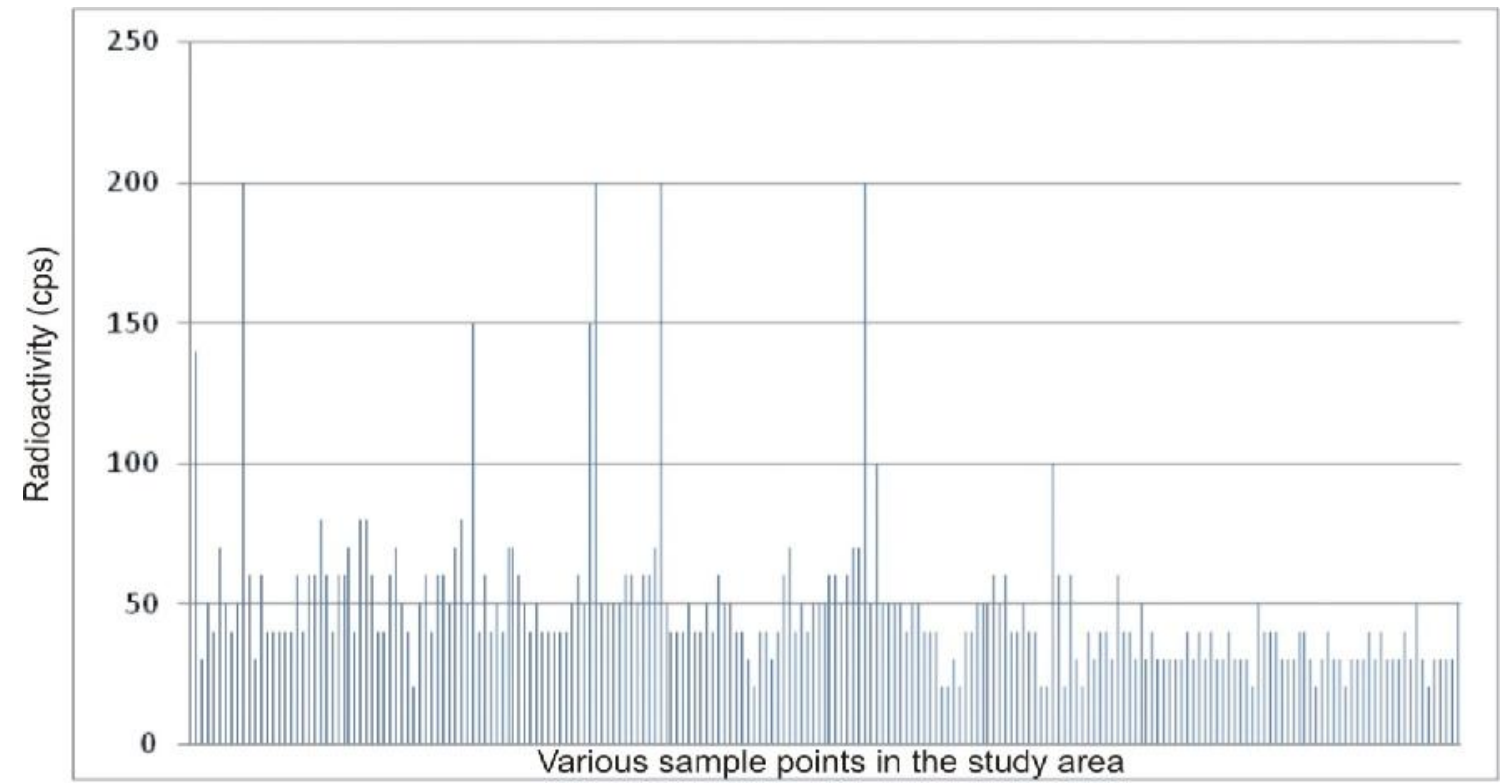

Fig. 3: Bar Chart of distribution of radioactivity in the study area

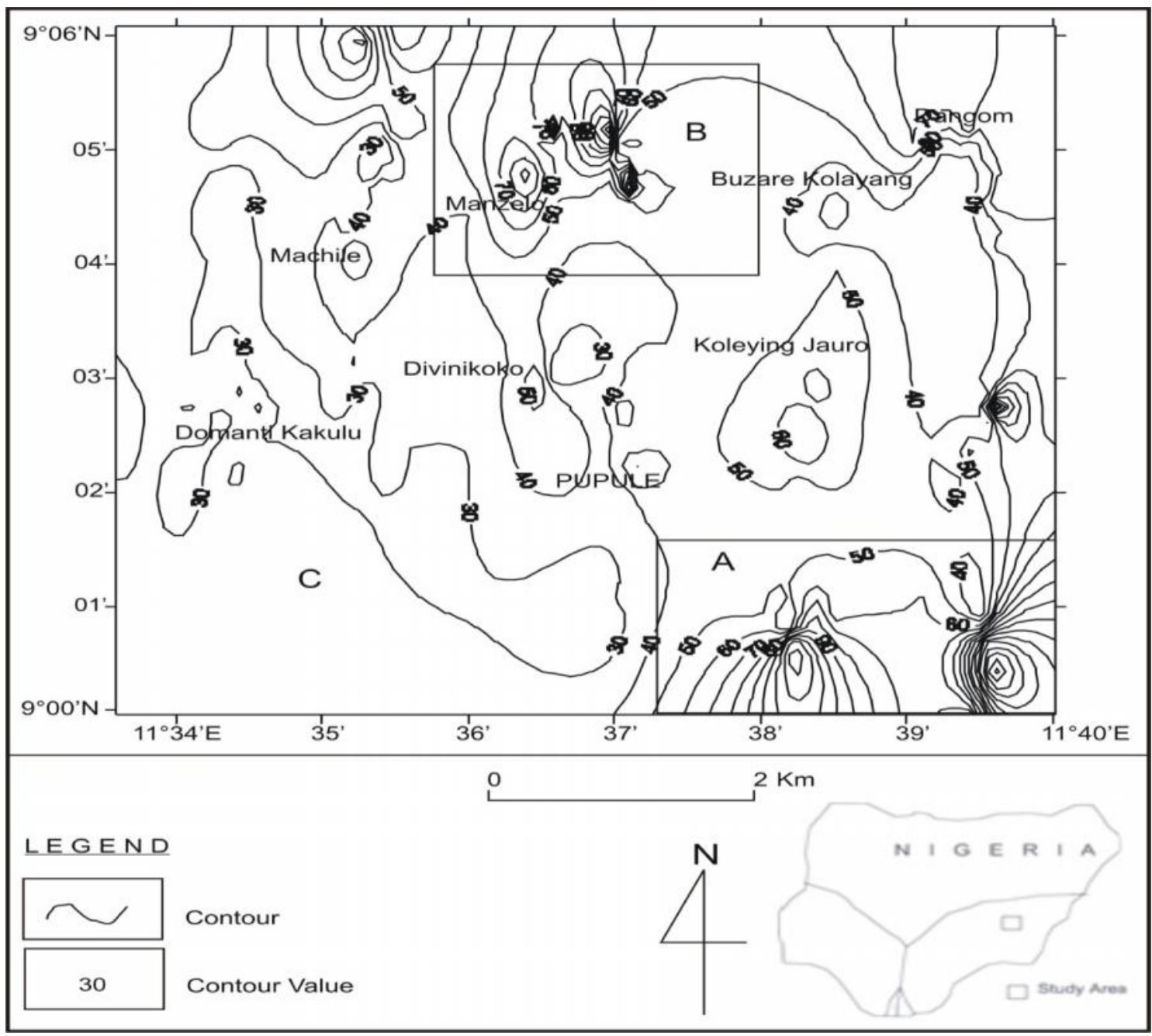

Fig. 4: Isorad map of Pupule. The contour lines show lines of equal radioactivity

In Figure 4, the relative spacing of the contour lines indicates the relative gradient of the radioactivity. The having radioactivity values within the limits defined by the two enclosing contours. On the map therefore, lines 
represented by the highest values, then lines connecting points of next highest radioactivity and so on. However, such values may not be clearly seen when the clustering of lines is intense as is the case of Figure 4, hence the need for a Bar Chart (Fig. 3).

From Figure 4, two populations of data are evident. These are represented by areas ' $A$ ' and ' $B$ ' in the figure. Area ' $A$ ' lies within the fine-grained granite, south of Koleying Jauro while area ' $B$ ' is situated within the porphyritic granite west of Buzare Kolayang. Although these areas have the highest radioactivity, the values form only $2.3 \%$ (Table 2 ) of the entire data. The remaining areas marked ' $\mathrm{C}$ ' contains the background counts. The map shows the location, size and shape of the areas of greatest radioactivity and may therefore provide a clue to probable areas (if any) of radioactive minerals that might be followed up with a more detailed study.

\section{DISCUSSION}

The greater part of the study area (marked ' $\mathrm{C}$ ' on the map) is characterised by background radioactivity. This area covers all of the equigranular medium-grained granites and parts of the porphyritic and fine-grained granites. The slightly high values in the fine-grained granites are consistent with the results of similar studies carried out in other areas within the region that such rocks are uranium-enhanced. For instant, Haruna et al., (2011a) carried out similar work in Monkin and found that the fine-grained granites were enriched in uranium relative to other rock units. Clusters of high values on the isorad map are therefore likely areas for radioactive minerals like uranium. Thus, the elevated readings over fine-grained granites in an area (marked 'A') on the southeastern portion of the study area may be lithological rather than structural. The finegrained granites of Pupule are massive and lack structures. The radiometric values of $200 \mathrm{cps}$ over these fine-grained granites are far less than the $2400 \mathrm{cps}$ values recorded over the fine-grained granites of Monkin. The difference may be explained by the numerous fractures that characterized the fine-grained granites of Monkin. In Monkin, uranium mineralisation might have been structurally controlled. Such mineralization would commonly involve secondary remobilisation of uranium from the primary ore minerals and concentration of the secondary uranium in fractures in response to low temperature oxygen-bearing water. This leads to higher uranium concentration and therefore high radiometric values. The fairly enhanced radioactivity in the fine-grained granite of Pupule may be related to high background content rather than concentration of uranium minerals that would have justified further more detailed investigation in the area.

Similarly, the fairly elevated values in the porphyritic granites may be due to enclaves of finegrained granites within these rocks and probably the high background values. All rocks contain minute amount of uranium and pulses are always produced by cosmic rays. Therefore if a scintillometer is turned on, it will always record radioactivity (background) from these sources. Readings of about $150 \mathrm{cps}$, just above the background values of $100 \mathrm{cps}$, are probably the result of sparsely distributed minerals of low radioactive content, which because of the mass effect has caused the enhanced readings, but which may be of no significance as an attractive area for further search.

\section{CONCLUSION}

Geologic field mapping and radiometric investigation of Pupule and environs does not support the area as promising for a more detailed uranium search. Geologic field mapping shows that the area like most other parts of the region is underlain predominantly by equigranular granites, porphyritic granites and subordinate finegrained granites. However, data obtained from the radiometric investigation indicate only fairly enhanced radiometric values of $200 \mathrm{cps}$ above the background counts of $100 \mathrm{cps}$. Data treatment and interpretation of the result suggest that the fairly enhanced radioactivity in the fine-grained granite, southeast of Pupule, may be related to high background values rather than concentration of uranium minerals that would have justified more detailed investigation in the study area.

\section{ACKNOWLEDGEMENT}

This work benefited immensely from the field assistance of Abubakar F. Abubakar and Adodo O. Catherine whom the author is greatly indebted. The author thanks Mr. Julius Bajabu of Nigeria Geological Survey Agency for providing a Scintillometer for the field work.

\section{REFERENCES}

Funtua, I. I., Okujeni, C. D., Elegba, S. B and Mustapha, A. O., 1992. Bioggeochemical Technique applied in uranium exploration. J. of Mining Geol. 28, 158161.

Funtua, I. I and Okujeni, C. D., 1996. Elements distribution patterns in the uranium occurrence at Mika, Northeastern Nigeria. Chemie der Erde, 56, 215-260.

Geological Survey of Nigeria, (1974). Geological map of Nigeria, scale: 1:2,000,000.

Haruna, I. V., Orazulike, D. M and Ofulume, A. B., 2011a. Preliminary geological and radiometric studies of the granitoids of Zing-Monkin area. Global Journal of Geological Sciences, 9, (2): 123-129.

Haruna, I. V., Valdon, Y. B and Mamman, Y. D., 2011b. Uranium prospecting in an area around Mika, Adamawa Massif, N.E. Nigeria: A Research Note. A Research Note. African Journal Of Physical Sciences, 7, (3): 105-109.

Haruna, I. V., Orazulike, D. M., Ofulume, A. B and Mamman, Y. D., 2011. Petrochemical and mineralogical constraints on the source and processes of uranium mineralization in the Granitoids of ZingMonkin area, Adamawa Massif, N.E Nigeria. Natural Resources Research, 20, (4): 355-366.

Haruna, I. V., Ahmed, H. A and Ahmed, A. S., 2012a. Geology and Tectono-sedimentary disposition of the Bima Sandstone of the Upper Benue Trough (Nigeria): Implications for sandstone-hosted 
uranium deposits. Journal of Geology and Mining Research, 4, (7): 168-173.

Haruna, I. V., Ahmed, H. A and Ahmed, A. S., 2012b. Uranium favourability study in an area around Pantishawa, Adamawa Massif, N.E. Nigeria: A research Note. International Journal of Scientific Research, 2, (3): 125-131.

Ogunleye, P. O and Okujeni, C. D., 1993. The Geology and geochemistry of the Zona uranium occurrence, Upper Benue Trough N.E. Nigeria. Journ. of Mining Geology. 2, 175-182.

Okujeni, C. D., Funtua, I. I., Ogunmakunwa, Z. A., Abba, S. I and Edegbo, S., 1988. Geochemical orientation survey for uranium in the Peta Syncline and Guburunde horst, Upper Benue Trough Nigeria. J. Sci. Res. 1, No.2.
Uranium Resources, Production and Demand., 2014. A joint report by the OECD Nuclear Energy Agency and the International Atomic Energy Agency, 334-343.

A Joint Report by the Organisation for Economic Cooperation and Development (OECD) (2014). Uranium 2014: Resources, Production and Demand, $187 \& 319$. 